\title{
Positron Annihilation Spectroscopy Study on Annealing Effect of CuO Nanoparticles
}

\author{
Jianjian Shi ${ }^{a}$, Jiaheng Wang ${ }^{a}$, Wei Yang ${ }^{a}$, Zhejie Zhu ${ }^{a}$, Yichu Wu ${ }^{a *}$ \\ ${ }^{a}$ School of Physics and Technology, Hubei Key Laboratory of Nuclear Solid State Physics, \\ Wuhan University - WHU, Wuhan, 430072, China.
}

Received: August 23, 2015; Revised: December 9, 2015; Accepted: December 17, 2015

\begin{abstract}
The microstructure and defects of $\mathrm{CuO}$ nanoparticles under isochronal annealing were investigated by positron annihilation spectroscopy (PAS), X-ray diffraction (XRD) and scanning electron microscope (SEM). XRD and SEM results indicated that the average grain sizes of $\mathrm{CuO}$ nanoparticles grew slowly below $800^{\circ} \mathrm{C}$, and then increased rapidly with the annealing temperature from 800 to $1000{ }^{\circ} \mathrm{C}$. Positron lifetime analysis exhibited that positrons were mainly annihilated in mono-vacancies $\left(V_{C u}, V_{O}\right)$ and vacancy clusters when annealing from 200 to $800^{\circ} \mathrm{C}$. Furthermore, $W-S$ plot of Doppler broadening spectra at different annealing temperatures found that the $(W, S)$ points distributed on two different defect species, which suggested that $V_{C u}^{-}-V_{O}^{+}$complexes were produced when the grains grew to bigger size after annealing above $800{ }^{\circ} \mathrm{C}$, and positrons might annihilate at these complexes.
\end{abstract}

Keywords: positron annihilation, defect, nanoparticle, $\mathrm{CuO}$

\section{Introduction}

Cupric oxide $(\mathrm{CuO})$ is a well-known $p$-type semiconductor material with an indirect band gap of $1.0 \mathrm{eV}^{1}$, which has attracted a large number of studies in polycrystalline as well as single crystal of $\mathrm{CuO}$ by using a variety of techniques. Especially, nano-sized $\mathrm{CuO}$ has raised the most prospective applications over the years, such as gas sensors ${ }^{2}$, catalysis ${ }^{3,4}$, supercapacitor $^{5,6}$, ceramics ${ }^{7}$, batteries ${ }^{8}$, solar energy cells ${ }^{9}$ and field emission emitters ${ }^{10}$.

Though $\mathrm{CuO}$ has numerous potential applications, the lack of control over the defects is still a big problem for practical devices. It has been found that the grain surface and interface are rich of defects such as vacancies $\left(V_{C u}\right.$ or $V_{O}$, where the subscript refers to the missing host atom), antisite defects $\left(C u_{O}\right.$ or $O_{C u}$, where $A_{\mathrm{B}}$ means " $B$ " atom is replaced by " $A$ " atom) and isolated interstitials $\left(O_{i}\right.$ or $\left.C u_{i}\right)$. However, the high formation energies of these defects lead to an unstable state at equilibrium ${ }^{11}$. These defects offer a scope to tune the useful material properties through proper choice of annealing environment and temperature. The negatively charged vacancy, $V_{C u}^{2-}$, where the superscript refers to the charge $q(-2)$ of the defect, is thought to be the source of $\mathrm{CuO}$ having $p$-type conductivity ${ }^{12,13}$. Gao et al. ${ }^{14}$ reported that oxygen vacancies at the interface of the particles were suggested to be responsible for the ferromagnetism in the $\mathrm{CuO}$ nanoparticles, vacuum annealing enhanced the ferromagnetism of the $\mathrm{CuO}$ nanoparticles, while oxygen atmosphere annealing reduced it. Shi et al. ${ }^{15}$ found that the tunable ferromagnetism for the $\mathrm{Cu}_{2} \mathrm{O} / \mathrm{Cu}$ nanoparticles composites was attributed to $\mathrm{Cu}$ vacancies at the interfaces.

With a large surface to volume ratio, surface effects dominate nanoparticles properties over their respective bulk features. $\mathrm{CuO}$ nanoparticles exhibit unique optical, electrical, and magnetic properties based on the effects of grain size and quantum dots size as the surface contribution

*e-mail: ycwu@whu.edu.cn becomes dominant ${ }^{16-19}$. Positron annihilation spectroscopy (PAS) has been used as a sensitive probe to characterize surface and interface defects in nanoctystalline metals ${ }^{20-22}$ and semiconductor nanoparticles ${ }^{23-25}$. This is mainly due to the fact that the size of nanoparticles is much smaller than the positron diffusion length $\left(L_{+} \sim 100 \mathrm{~nm}\right)^{26}$. Positrons are trapped at defects such as open volumes (vacancies, vacancy clusters and voids) located at the grain surface or interface. Therefore, the positron annihilation radiation parameters provide information on the microstructure of grain surfaces or interfaces. Positron lifetime annihilation parameters can be directly correlated to the size and concentration of defects at the surfaces or interfaces. Doppler broadening parameters give information about the electron momentum distribution at the annihilation site ${ }^{27}$. Some authors investigated defect structure of $\mathrm{CuO}$ nanoparticles by positron annihilation technology ${ }^{28-30}$. They found that there existed a large number of copper- and/or oxygen- related vacancies or complexes in $\mathrm{CuO}$ nanoparticles, which depended on the annealing environment and temperature. However, it should be mentioned that the feature of defects in different sizes of $\mathrm{CuO}$ nanoparticles is far from understood and requires extensive studies in $\mathrm{CuO}$ nanoparticles. In this work, the generation and recovery of defects located at grain surfaces or interfaces in $\mathrm{CuO}$ nanoparticles under isochronal annealing were investigated by positron annihilation lifetime and Doppler broadening spectroscopy, together with traditional $\mathrm{XRD}$ and SEM techniques.

\section{Experimental}

\subsection{Sample preparation}

$\mathrm{CuO}$ nanoparticles with a size of about $40 \mathrm{~nm}$ were purchased from Beijing dekedaojin High Technology Ltd, China with a purity of $99.9 \%$. The nanoparticle powders 
were hand milled for $2 \mathrm{~h}$ in an agate mortar with a pestle and then pressed into pellets (diameter: $15 \mathrm{~mm}$, thickness: $1 \mathrm{~mm}$ ) under a static pressure of about $10 \mathrm{MPa}$ for $5 \mathrm{~min}$ at room temperature. The annealing experiments were made over a temperature range in the stable region of the $\mathrm{CuO}$ phase, i.e. $T<1027^{\circ} \mathrm{C}^{1,31}$. So, the samples were isochronally annealed at different temperature of 200, 400, 600, 700, 800,900 and $1000{ }^{\circ} \mathrm{C}$ in air for a constant duration $(2 \mathrm{~h})$.

\subsection{Experimental method}

$\mathrm{XRD}$ analysis was performed by using $\mathrm{Cu}-\mathrm{K}_{\alpha}$ radiation $(\lambda=1.5406 \AA)$ on "Bruker D8" X-ray diffractometer. Si crystal was used as an external standard to correct for the instrument line broadening. Data were collected from $20^{\circ}$ to $80^{\circ}(2 \theta)$ with a step size of $0.02^{\circ}$. There were no monochromators in the whole XRD system. Thus there occurred $\mathrm{Cu}-\mathrm{K}_{\alpha 1}$ and $\mathrm{Cu}-\mathrm{K}_{\alpha 2}$ radiation at the same time, and each Bragg reflect ion took place with slightly different diffraction angles. When the XRD data were processed, the contribution of $\mathrm{Cu}-\mathrm{K}_{\alpha 2}$ was stripped by using Jade software and only the pure $\mathrm{Cu}-\mathrm{K}_{\alpha 1}$ radiation was left. The average particle sizes were determined by Debye-Scherrer formula. The morphology of the samples was investigated by a Hitachi S-4800 field emission scanning electron microscope (SEM).

Positron annihilation lifetime spectroscopy (PALS) was performed using a conventional fast-fast coincidence system with a temporal resolution of about 280 ps. A ${ }^{22} \mathrm{Na}$ positron source with intensity of about $20 \mu \mathrm{Ci}$ was used. The positron source of ${ }^{22} \mathrm{Na}$ was sealed between two Kapton films. Each spectrum was collected with a total count of $1 \times 10^{6}$. During the measurement, the positron source was sandwiched between two identical sample pieces. The components of the positron annihilation in the source and Kapton films were carried out using Si single crystal as reference. The spectra were analyzed using an analysis software (LT, version 9) $)^{32}$ based on the sum of the exponential decay curves given by the following equation:

$-\frac{d n(t)}{d t}=\sum_{i}^{n} I_{i} \tau_{i} \exp \left(-\tau_{i} t\right), \sum_{i}^{n} I_{i}=1$

Where $n(t)$ is that the positron is alive at time $t$ after its birth and $\tau_{i}$ is the lifetime associated with a decay curve with its initial intensity, $I_{\mathrm{i}}$. Two lifetime components $\tau_{1}, \tau_{2}$, and corresponding percentage intensities, $I_{1}, I_{2}$, were resolved in the case of the $\mathrm{CuO}$ nanoparticles samples.

Doppler broadening spectroscopy (DBS) was measured using a liquid-nitrogen cooled high-purity (HP)-Ge detector with an energy resolution of about $1.50 \mathrm{keV}$ at $511 \mathrm{keV}$. The source is sandwiched between the sample pair similar to positron lifetime experiments. The DBS were characterized by shape $(S)$ and wing $(W)$ parameters, which are linked to the interaction of the electron-positron pair with low-momentum valance electrons and high-momentum core electrons, respectively. The $S$ and $W$ parameters were defined respectively as the ratio of the central region $(511 \pm 0.8 \mathrm{keV})$ and the wing region $(511 \pm 3.4$ to $511 \pm 6.8 \mathrm{keV})$ of the spectrum to the entire region of the spectrum.

\section{Results and discussion}

The XRD patterns for all the samples are showed in Figure $1(\mathrm{a})$. No peaks of impurity phases $\left(\mathrm{Cu}_{2} \mathrm{O}\right.$ or $\left.\mathrm{Cu}\right)$ are detected in these XRD patterns. All diffraction peaks as the typical monoclinic structure of $\mathrm{CuO}$ are observed, which show that the experimental samples are located in the $\mathrm{CuO}$ stable region when annealing in the temperature ranging from 200 to $1000{ }^{\circ} \mathrm{C}$ for $2 \mathrm{~h}$. The whole $\mathrm{CuO}$ planes are used to calculate the average grain size. The average grain size of the $\mathrm{CuO}$ samples, as is shown in Figure 1(b), is calculated from the full width at half maximum of their diffraction curves by using Debye-Scherrer formula ${ }^{33}$, i.e.

$D=K \lambda / \beta \cos \theta$

Where $D$ is the particle size, $K$ is the constant shape factor (taken as 0.89 ), $\lambda$ is taken as the wavelength of $\mathrm{X}$-ray radiation, $\beta$ is the full width at half maximum (FWHM) of the XRD peak, and $\theta$ is the Bragg angle. The calculated average grain size of the as-pressured sample is about $36.8 \pm 3 \mathrm{~nm}$, which is consistent with the information provided by the vendors. The size of the $\mathrm{CuO}$ nanoparticles increases slowly with increasing annealing temperature in annealing temperature from 200 to $800{ }^{\circ} \mathrm{C}$. Similar observations have also been reported by earlier literature ${ }^{16}$. When the samples are annealed from 800 to $1000{ }^{\circ} \mathrm{C}$, the grain size increases from 43 to $60 \mathrm{~nm}$ accordingly.
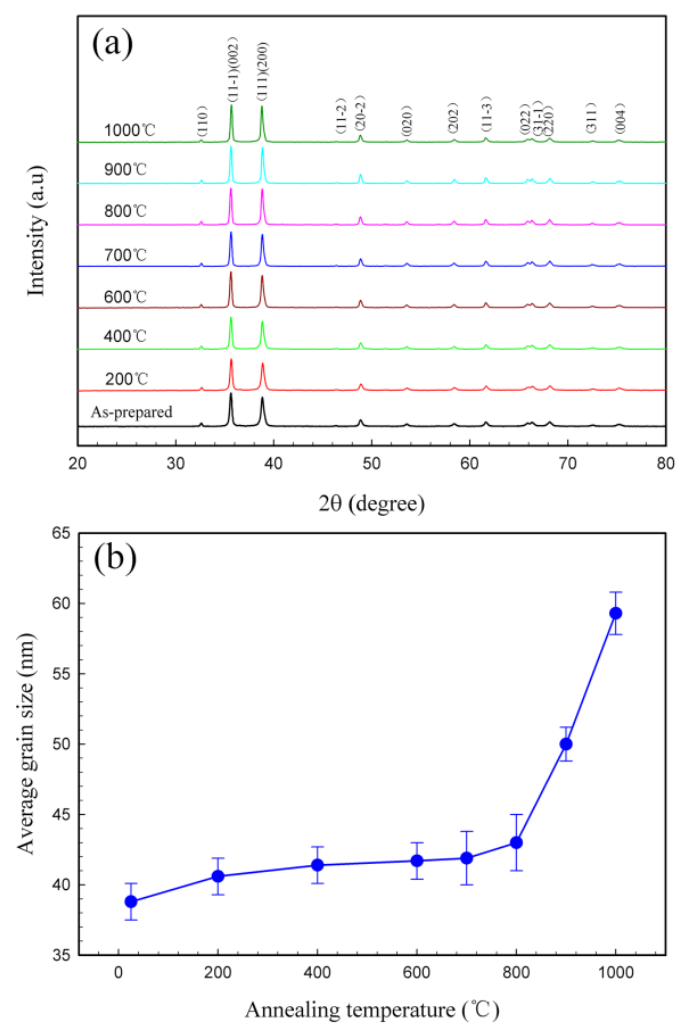

Figure 1. XRD patterns (a) and average grain size (b) of the $\mathrm{CuO}$ nanoparticles as a function of annealing temperature. 
SEM images of $\mathrm{CuO}$ samples annealed at different temperatures are depicted in Figure 2. The testing part is the cross section of the $\mathrm{CuO}$ pellets. It can be seen that the $\mathrm{CuO}$ morphologies are not significantly changed below $800^{\circ} \mathrm{C}$. The $\mathrm{CuO}$ nanoparticles annealed at $800^{\circ} \mathrm{C}$ began to aggregate into bigger particles, leading to an increase of grain size. These particles have a greater tendency to form clusters or aggregates when increasing the annealing temperature. However, due to limited resolution of SEM, the size of the $\mathrm{CuO}$ nanoparticles that assemble into micro-size cannot be estimated from the observed images, these grains have a very large average size $(100-2500 \mathrm{~nm})$ compared to that obtained by XRD analysis $(40-60 \mathrm{~nm})$. The crystallization of $\mathrm{CuO}$ nanoparticles is evidently improved with increasing the annealing temperature. This indicates that the grains are clusters of crystallites, consistent with results obtained previously ${ }^{16,19}$.

In order to further analyze the generation and recovery of defects located at grain surfaces or interfaces in $\mathrm{CuO}$ nanoparticles under isochronal annealing, we performed positron lifetime and Doppler broadening measurements. Figure 3(a) and Figure 3(b) show the positron lifetime parameters $\tau_{1}, \tau_{2}$, and their corresponding percentage intensities, $I_{1}, I_{2}$ as a function of annealing temperature in the case of the $\mathrm{CuO}$ nanoparticles samples. No meaningful change in two lifetimes $\left(\tau_{1}\right.$ and $\left.\tau_{2}\right)$ and their corresponding percentage intensities $\left(I_{1}\right.$ and $\left.I_{2}\right)$ are observed when the annealing temperature increases from 200 to $800{ }^{\circ} \mathrm{C}$. Although the observed annihilation spectra in these samples appear to be two components, the simultaneous decrease in $I_{2}$ and $\tau_{1}$ rules out the two-state trapping model which show a decrease in $I_{2}$ is accompanied by an increase in the $\tau_{1}$ value $^{34}$. Therefore, the short lifetime $\tau_{1}$ cannot be exclusively attributed to positrons annihilated in the bulk of $\mathrm{CuO}$. So, the short lifetime is associated with trapping at the bulk or mono-vacancy defects, and the long lifetime is assigned to trapped positrons in large vacancy clusters at the grain interfaces ${ }^{29}$. As seen in Figure 3, when the $\mathrm{CuO}$ nanoparticles is annealed at $200{ }^{\circ} \mathrm{C}$, an increase in $\tau_{1}, \tau_{2}$ and $I_{1}$ while a decrease in $I_{2}$ has been observed. The defect states of the as-pressured sample (at room temperature) might be different from that of the sample sintered at $200{ }^{\circ} \mathrm{C}$. When the $\mathrm{CuO}$ nanoparticles was annealed at $200{ }^{\circ} \mathrm{C}$, the supply of small thermal energy conduced intragrain $\mathrm{Cu}$ and $\mathrm{O}$ vacancies to migrate towards the grain surfaces or interfaces. A rearrangement of nanoparticles would lead to the formation of more two-grain interfaces accompanied by a reduction in the number of three-grain junctions in the as-pressured sample without annealing. We observe that a small increase of $\tau_{1}$, around $185 \mathrm{ps}$, is associated with positron trapping at vacancy-type defects in the two-grain interfaces, $\tau_{2}$ increases from 308 to 360 ps due to positrons trapping at larger-size vacancy clusters in three-grain junctions ${ }^{28}$, while the decrease of $I_{2}$ may be due to a reduction in the number of three-grain junctions. The bulk lifetime of about $169 \mathrm{ps}$ in $\mathrm{CuO}$ was fixed according to the previous PALS studies ${ }^{29,35}$. The value of $\tau_{1}(\sim 180 \mathrm{ps})$ is between the lifetime of positron annihilation in a bulk (169 ps) and a $\mathrm{Cu}$ mono-vacancy (230 ps) ${ }^{29}$. Hence, the value of $\tau_{1}$ is attributed to a mixed contribution from the annihilation of trapped positrons in $\mathrm{CuO}$ bulk and mono-vacancies ${ }^{28}$. In the case of sample annealing at $1000{ }^{\circ} \mathrm{C}$, with the largest average grain size $59.3 \mathrm{~nm}, I_{2}$ decreases up to $2.2 \%$ and $\tau_{1}$ results in a value of $165.8 \mathrm{ps}$ which closes to the lifetime of positrons trapped at the $\mathrm{CuO}$ bulk. This likely indicates that positrons are mainly annihilated in the $\mathrm{CuO}$ bulk and $V_{\mathrm{Cu}}$ are absent in the $\mathrm{CuO}$ nanoparticles annealing at $1000{ }^{\circ} \mathrm{C}$.

It is well-known that positrons were mainly trapped at neutrally or negatively charged (anion) vacancies and rarely trapped at positively charged (cation) vacancies since the probability of the positron annihilation with $1 \mathrm{~s}$ electrons of oxygen was small owing to a strong Coulomb repulsion of the nucleus. The positron density concentrating near $\mathrm{Cu}-\mathrm{O}$ bonds ${ }^{36}$ and the shortest distance $(1.95 \AA)$ between $\mathrm{Cu}$ and $\mathrm{O}$ ions in a monoclinic cell of $\mathrm{CuO}$ were identified ${ }^{37}$. Therefore the effects of positron trapping at positively charged vacancies
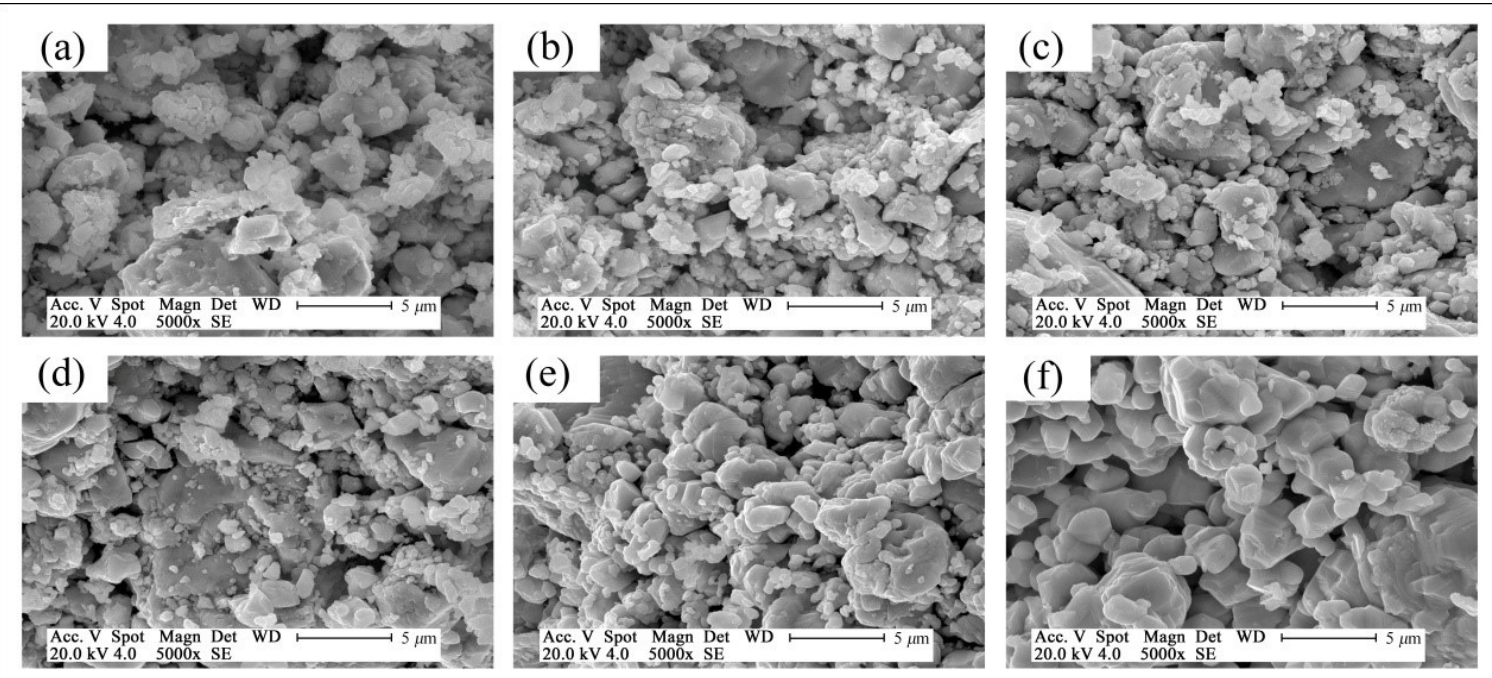

Figure 2. SEM images of $\mathrm{CuO}$ nanoparticles annealing at (a) room temperature $\left(25^{\circ} \mathrm{C}\right)$, (b) $400{ }^{\circ} \mathrm{C}$, (c) $600{ }^{\circ} \mathrm{C}$, (d) $700{ }^{\circ} \mathrm{C}$, (e) $800{ }^{\circ} \mathrm{C}$, and (f) $1000{ }^{\circ} \mathrm{C}$. 
cannot be neglected completely. A first-principles calculation of Wu et al. ${ }^{12}$ found that only the $V_{C u}, V_{O}, C u_{i}$ and $O_{C u}$ had one stable charge state $V_{\mathrm{Cu}}^{2-}, V_{O}^{0}, \mathrm{Cu}_{i}^{0}$ and $\mathrm{O}_{\mathrm{Cu}}^{2-}$ in the whole range of the Fermi level in both $n$-type and $p$-type $\mathrm{CuO}$ in the O-rich environment, respectively. Meanwhile, the formation energy of $\mathrm{Cu}$ vacancies is lower than other type's defects, and the most stable defects, $\mathrm{Cu}$ vacancies, were also identified in $\mathrm{CuO}$. Other vacancy-type defects found in $\mathrm{CuO}$ are $V_{O}$, but since the formation energy to $V_{O}$ is around $3.5 \mathrm{eV}$, which is much larger than that of $V_{C u}$ (less than $\left.1.0 \mathrm{eV}\right), V_{O}$ may also be trapped positrons. The results of theoretical calculation and experiment in cuprate superconductors have proved that the dominant positron traps were presented by oxygen vacancy defects in the $\mathrm{Cu}-\mathrm{O}$ planes ${ }^{38-40}$. It was also reported that open volumes which were mainly identified as anion vacancy defects existed in the grain interfaces in the $\mathrm{CuO}$ nanoceramics as well as the oxygen vacancy defects led to a decrease in the degree of $\mathrm{Cu}-\mathrm{O}$ bond covalency studied by $\mathrm{PAS}^{30}$. Therefore, in present study, we consider that the effects of positron trapping at positively charged vacancies $\left(V_{o}\right)$ cannot be neglected. Positrons may be annihilated in both $V_{C u}$ and $V_{O}$ when the annealing temperatures varies from $200-800{ }^{\circ} \mathrm{C}$. This will be analyzed in the following discussion of $W-S$ plot.

The $S$ and $W$ parameters index the fraction of positron annihilating with the valence electrons and core electrons, respectively. The reduction in positron annihilation with core electrons is much more as compared to the valence electrons
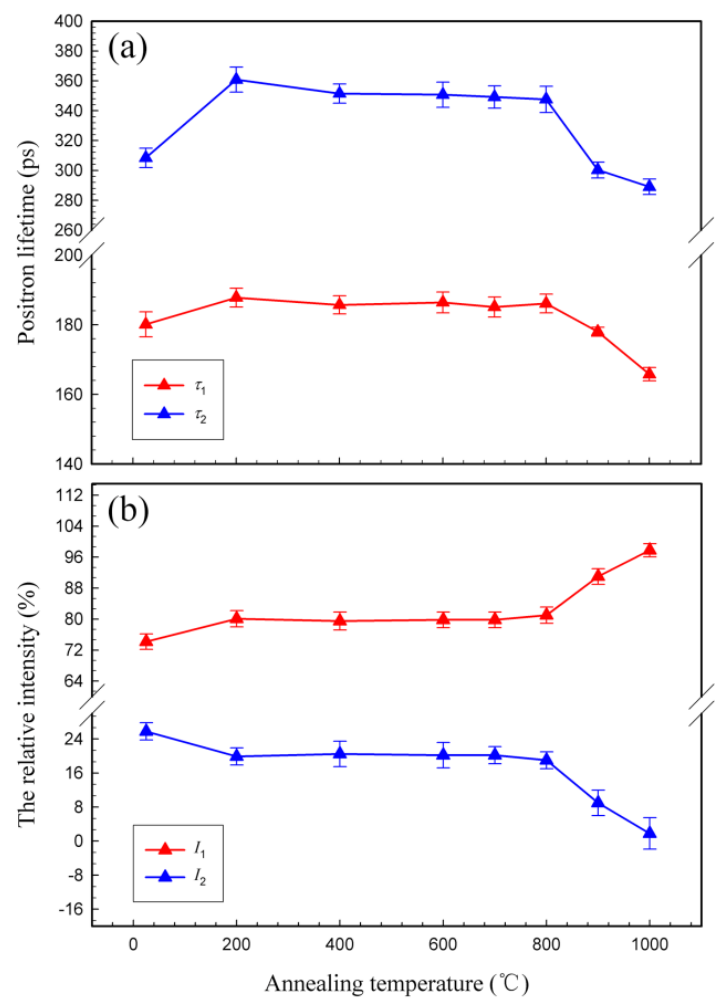

Figure 3. The $\mathrm{CuO}$ nanoparticles annealed at different temperature, (a) the positron lifetime values, $\tau_{1}, \tau_{2}$, (b) their corresponding percentage intensities, $I_{1}, I_{2}$. leading to the $S$ parameter is higher than $W$ parameter. Consequently, the data from DBS provides further insight on open volume defects (vacancies, vacancy clusters and voids). The $S$ parameter reveals that the information of the size and concentration of defects in the different annihilation sites of solids ${ }^{41}$ and can be correlated to the positron average lifetime $\left(\tau_{\mathrm{a}}\right)$, which is calculated by the following equation:

$\tau_{a}=\tau_{1} I_{1}+\tau_{2} I_{2}$

The $S$ parameter and $\tau_{\mathrm{a}}$ as a function of annealing temperature are shown in Figure 4. It is seen that both $S$ parameter and $\tau_{\mathrm{a}}$ show a similar trend. The $S$ parameter and $\tau$ decrease slightly with the annealing temperature from 200 to $800^{\circ} \mathrm{C}$ and decrease rapidly above $800^{\circ} \mathrm{C}$. It can be concluded that the total concentration of interfacial defects reduces with the increase of grain size. Similar results were observed in $\mathrm{ZnO}$ nanoparticles studied by Sharma et al. ${ }^{25}$.

Further discussion is from the set of $S$ and $W$ data plotted in the $W-S$ plane which reveals the information about the overall defect types, as is shown in Figure. 5. It is interesting to observe that the $(W, S)$ points distribute on two straight lines: first straight line segment from 200 to $800{ }^{\circ} \mathrm{C}$ and second straight line segment from 800 to $1000^{\circ} \mathrm{C}$. The straight line can be explained by the change in the concentration of the identical defect in the series samples ${ }^{42}$. It is indicated that the vacancy species are changed, producing two types of defects. As seen in Figure. 4(b), when the annealing
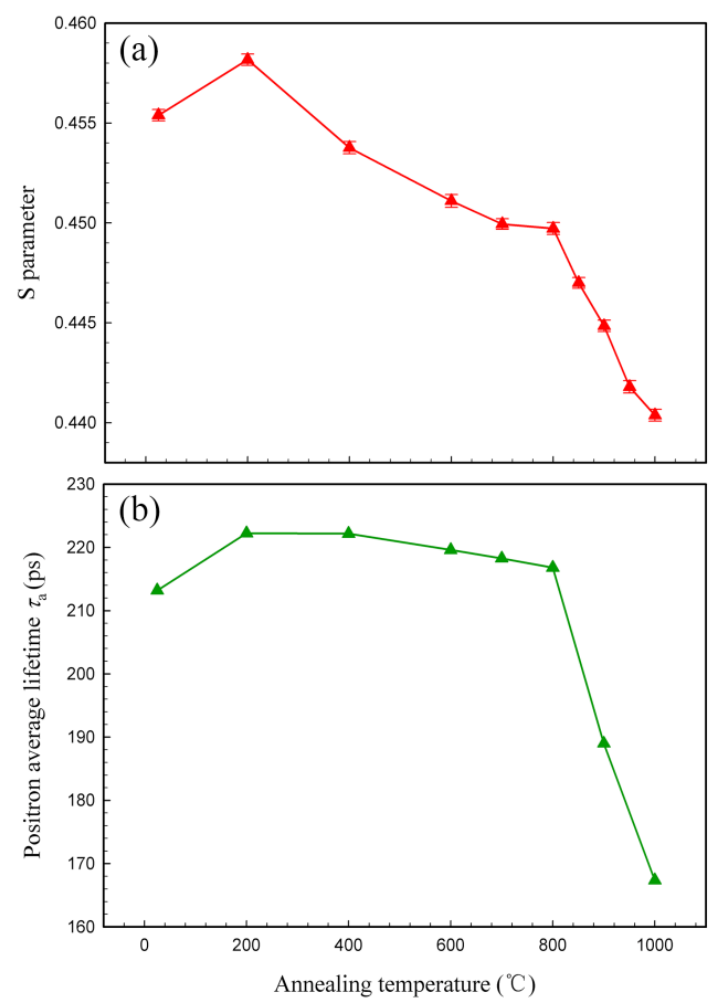

Figure 4. $S$ parameter (a) and positron average lifetime $\left(\tau_{\mathrm{a}}\right)(\mathrm{b})$ as a function of annealing temperature. 


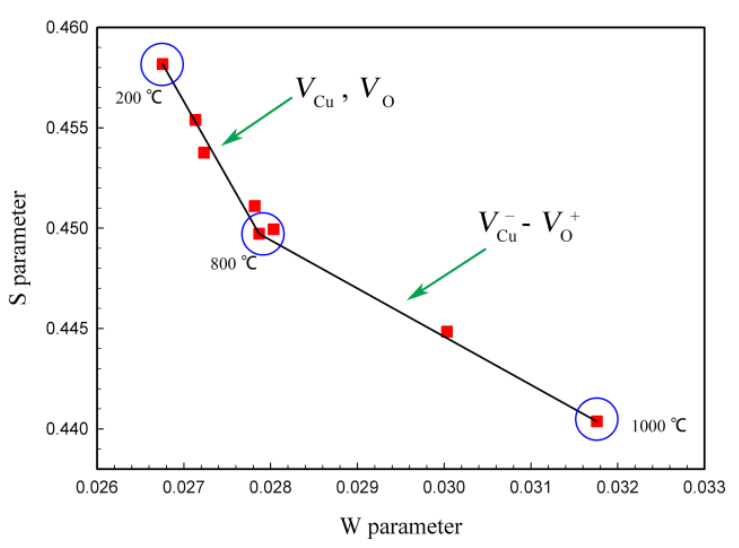

Figure 5. $W-S$ plot for $\mathrm{CuO}$ nanoparticles

temperature varies from 200 to $800{ }^{\circ} \mathrm{C}, \tau_{2}$, with a value of about $350 \mathrm{ps}$, is essentially constant and larger than the lifetime of $\mathrm{Cu}$ mono-vacancies $(230 \mathrm{ps})$. It can be understood that small-size $\mathrm{Cu}$ vacancies assemble and form the large-size $\mathrm{Cu}$ vacancy clusters at the grain interfaces. In addition, the effects of positron trapping at positively charged vacancies $\left(V_{o}\right)$ cannot be also neglected when annealing below $800^{\circ} \mathrm{C}$. So, the first straight line is attributed to positrons annihilating in mono-vacancies (both $V_{C u}$ and $V_{O}$ ) and vacancy clusters at grains in $\mathrm{CuO}$ nanoparticles. When annealing above $800{ }^{\circ} \mathrm{C}$, both $\tau_{2}$ and $I_{2}$ begin to decrease rapidly while $I_{1}$ increases up to $97.8 \%$. In this case, since the two trapping model is not suitable for explaining the behavior of positron annihilation parameters, a new complex structure of defects may be formed. Cruz et al. ${ }^{43}$ identified that oxygen vacancies existed in $\mathrm{Cu}_{2} \mathrm{O}$ single crystals annealing in air atmosphere at $923^{\circ} \mathrm{C}$ in the stable region of the $\mathrm{CuO}$ phase as well as a lifetime of $320 \pm 40 \mathrm{ps}$ was attributed to positrons trapped at $V_{C u}^{-}-V_{O}^{+}$complexes. In present experiment, the value of $\tau_{2}$ is close to the lifetime of the $V_{C u}^{-}-V_{O}^{+}$complexes $(320 \pm 40 \mathrm{ps})$, therefore, it is suggested that $V_{C u}^{-}-V_{O}^{+}$complexes at the grain interfaces may be formed due to fast diffusion of $V_{C u}$ and

\section{References}

1. Heinemann M, Eifert B, Heiliger C. Band structure and phase stability of the copper oxides $\mathrm{Cu}_{2} \mathrm{O}, \mathrm{CuO}$, and $\mathrm{Cu}_{4} \mathrm{O}_{3}$. Physical Review B. 2013;87(2):115111. DOI:http://dx.doi.org/10.1103/ PhysRevB.87.115111

2. Kim H, Jin C, Park S, Kim S, Lee C. H2S gas sensing properties of bare and $\mathrm{Pd}$-functionalized $\mathrm{CuO}$ nanorods. Sensors and Actuators B: Chemical. 2012; 161(1-3): 594-599.

3. Santos A, Yustos P, Quintanilla A, Ruiz G, Garcia-Ochoa F. Study of the copper leaching in the wet oxidation of phenol with CuO-based catalysts: causes and effects. Applied Catalysis B: Environmental. 2005;61(3-4):323-333. DOI: 10.1016/j. apcatb.2005.06.006

4. Carnes CL, Klabund KJ. The catalytic methanol synthesis over nanoparticle metal oxide catalysts. Journal of Molecular Catalysis A: Chemical. 2003; 194(1-2): 227-236.

5. Pendashteh A, Mousavi MF, Rahmanifar MS. Fabrication of anchored copper oxide nanoparticles on graphene oxide
$V_{o}$ when annealing above $800{ }^{\circ} \mathrm{C}$, together with aggregates and growth of $\mathrm{CuO}$ nanoparticles. It can be concluded that when annealing temperature below $800{ }^{\circ} \mathrm{C}$ (first straight line segment of Figure 5), positrons are mainly annihilated in mono-vacancies $\left(V_{C u}, V_{O}\right)$ and vacancy clusters, while some positrons may annihilate in $V_{C u}^{-}-V_{O}^{+}$complexes above $800{ }^{\circ} \mathrm{C}$ (second straight line segment of Figure 5). Further work is needed to study the different annealing environment of $\mathrm{CuO}$ nanoparticles.

\section{Conclusions}

The microstructure and defects of $\mathrm{CuO}$ nanoparticles under isochronal annealing were studied by XRD, SEM and PAS. XRD results indicated that the average grain sizes of $\mathrm{CuO}$ nanoparticles varied from 40 to $60 \mathrm{~nm}$. The crystallite of $\mathrm{CuO}$ nanoparticles grew slowly below 800 ${ }^{\circ} \mathrm{C}$, and then nanoparticles increased with the annealing temperature up to $1000{ }^{\circ} \mathrm{C}$. SEM images also indicated that the $\mathrm{CuO}$ nanoparticles annealed at $800{ }^{\circ} \mathrm{C}$ have began to aggregate into bigger particles, which were consistent with the growth of $\mathrm{CuO}$ nanoparticles seen in XRD patterns. PAS revealed that both $S$ parameter and $\tau_{\mathrm{a}}$ decreased slightly with the annealing temperature from 200 to $800{ }^{\circ} \mathrm{C}$ and decreased rapidly above $800{ }^{\circ} \mathrm{C}$. The total concentration of interfacial defects in $\mathrm{CuO}$ nanoparticles reduced with the increase of grain size. PALS exhibited that the short lifetime, $\tau_{1}$, which was attributed to a mixed contribution from the annihilation of trapped positrons in the bulk and mono-vacancies $\left(V_{C u}, V_{O}\right)$, and the long lifetime, $\tau_{2}$, which was assigned to trapped positrons in large vacancy clusters below $800{ }^{\circ} \mathrm{C}$. $W-S$ plot of DBS found that the $(W, S)$ points distributed on two different straight lines, which suggested that $V_{C u}^{-}-V_{O}^{+}$complexes were produced with the increase of grain size after annealing above $800{ }^{\circ} \mathrm{C}$, positrons might annihilate at these complexes.

\section{Acknowledgements}

This work was supported by National Natural Science Foundation of China (11175136, 51071111, J1210061).

nanosheets via an electrostatic coprecipitation and its application as supercapacitor. Electrochimica Acta. 2013; 88:347-357. DOI:10.1016/j.electacta.2012.10.088

6. Dubal DP, Dhawale DS, Salunkhe RR, Jamdade VS, Lokhande CD. Fabrication of copper oxide multilayer nanosheets for supercapacitor application. Journal of Alloys and Compounds. 2010;492(1-2):26-36. DOI: 10.1016/j.jallcom.2009.11.149

7. Mostovshchikova EV, Gizhevskii BA, Loshkareva NN, Galakhov VR, Naumov SV, Ponosov YS, et al. Infrared and $\mathrm{X}$-ray absorption spectra of $\mathrm{Cu} 2 \mathrm{O}$ and $\mathrm{CuO}$ nanoceramics. Solid State Phenomena. 2012;190:683-686. DOI 10.4028/ www.scientific.net/SSP.190.683

8. Sahay R, Suresh Kumar P, Aravindan V, Sundaramurthy J, Chui Ling W, Mhaisalkar SG, et al. High aspect ratio electrospun cuo nanofibers as anode material for lithium-ion batteries with superior cycleability. The Journal of Physical Chemistry C. 2012;116(34):18087-18092. DOI: 10.1021/jp3053949

9. Sahay R, Sundaramurthy J, Suresh Kumar P, Thavasi V, Mhaisalkar SG, Ramakrishna S. Synthesis and characterization 
of $\mathrm{CuO}$ nanofibers, and investigation for its suitability as blocking layer in ZnO NPs based dye sensitized solar cell and as photocatalyst in organic dye degradation. Journal of Solid State Chemistry. 2012;186:261-267.

10. Hsieh CT, Chen JM, Lin HH, Shih HC. Field emission from various $\mathrm{CuO}$ nanostructures. Applied Physics Letters. 2003;83(16):3383-3385.

11. Wu D. A first-principles study on bulk copper oxide: electronic structures and native point defects [Dissertation]. Arlington: University of Texas; 2005.

12. Wu D, Zhang Q, Tao M. LSDA+Ustudy of cupric oxide: Electronic structure and native point defects. Physical Review B. 2006;73(23):235206. DOI:http://dx.doi.org/10.1103/ PhysRevB.73.235206

13. Ray SC. Preparation of copper oxide thin film by the sol-gel-like dip technique and study of their structural and optical properties. Solar Energy Materials and Solar Cells. 2001;68(3-4):307-312.

14. Gao D, Zhang J, Zhu J, Qi J, Zhang Z, Sui W, et al. Vacancymediated magnetism in pure copper oxide nanoparticles. Nanoscale Research Letters. 2010;5(4): 769-772.

15. Shi S, Gao D, Xu Q, Yang Z, Xue D. Cu vacancies modulated the room temperature ferromagnetism in $\mathrm{Cu} 2 \mathrm{O} / \mathrm{Cu}$ nanoparticle composites. CrystEngComm. 2015;17(10):2118-2122. DOI: $10.1039 / \mathrm{C} 4 \mathrm{CE} 02542 \mathrm{C}$

16. Rehman S, Mumtaz A, Hasanain SK. Size effects on the magnetic and optical properties of $\mathrm{CuO}$ nanoparticles. Journal of Nanoparticle Research. 2010;13(6): 2497-2507.

17. Borgohain K, Singh JB, Rama Rao MV, Shripathi T, Mahamuni $\mathrm{S}$. Quantum size effects in $\mathrm{CuO}$ nanoparticles. Physical Review B. 2000;61(16):11093.

18. Krynetskiı̌ IB, Gizhevskiǔ BA, Naumov SV, Kozlov EA. Size effect of the thermal expansion of nanostructural copper oxide. Physics of the Solid State. 2008;50(4):756-758.

19. Rao GN, Yao YD, Chen JW. Evolution of size, morphology, and magnetic properties of $\mathrm{CuO}$ nanoparticles by thermal annealing. Journal of Applied Physics. 2009;105(9):093901.

20. Schaefer HE, Würschum R, Birringer R, Gleiter H. Structure of nanometer-sized polycrystalline iron investigated by positron lifetime spectroscopy. Physical Review B. 1988;38(14):95459554.

21. Segers D, Petegem SV, Löffler JF, Swygenhoven HV, Wagner W, Dauwe C. Positron annihilation study of nanocrystalline iron. Nanostructured Materials. 1999;12(5-8):1059-1062. doi:10.1016/S0965-9773(99)00299-8

22. Eldrup MM, Sanders PG, Weertman JR. Positron annihilation study of the influence of grain size and purity on the annealing behaviour of nano-crystalline copper. Materials Science Forum. 1997;255:436-438. DOI: 10.4028/www.scientific.net/MSF.255257.436

23. Eijt SW, van Veen AT, Schut H, Mijnarends PE, Denison AB, Barbiellini B, et al. Study of colloidal quantum-dot surfaces using an innovative thin-film positron 2D-ACAR method. Nature Materials. 2006;5(1):23-26. doi:10.1038/nmat1550

24. Weber MH, Lynn KG, Barbiellini B, Sterne PA, Denison AB. Direct observation of energy-gap scaling law in CdSe quantum dots with positrons. Physical Review B. 2002;66(4):041305(R). DOI: 10.1103/PhysRevB.66.041305

25. Sharma SK, Pujari PK, Sudarshan K, Dutta D, Mahapatra M, Godbole SV, et al. Positron annihilation studies in $\mathrm{ZnO}$ nanoparticles. Solid State Communications. 2009;149(1314):550-554.
26. Puska MJ, Nieminen RM. Theory of positrons in solids and on solid surfaces. Reviews of Modern Physics. 1994;66(3):841-899.

27. Siegel RW. Positron annihilation spectroscopy. Annual Review of Materials Science. 1980;10:393-425. DOI: 10.1146/annurev. ms.10.080180.002141

28. Pareja R, Delacruz RM. Sintering of $\mathrm{CuO}$ investigated by positron lifetime spectroscopy. Journal of Materials Science. 1991;26(3):593-596.

29. Ameena F. Defect studies in Cu-based P-type transparent conducting oxides. [Dissertation]. Arlington: University of Texas; 2012.

30. Druzhkov AP, Gizhevskii BA, Arbuzov VL, Kozlov EA, Shalnov $\mathrm{KV}$, Naumov SV, et al. Electronic and structural properties of micro-and nanometre-sized crystalline copper monoxide ceramics investigated by positron annihilation. Journal of Physics: Condensed Matter. 2002;14(34):7981-7990.

31. O'Keeffe M, Moore WJ. Thermodynamics of the formation and migration of defects in cuprous oxide. The Journal of Chemical Physics. 1962;36(11): 3009-3013. http://dx.doi. org/10.1063/1.1732418

32. Kansy J. Microcomputer program for analysis of positron annihilation lifetime spectra. Nuclear Instruments and Methods in Physics Research Section A. 1996; 374(2):235-244.

33. Warren BE. X-ray Diffraction. Massachusetts: Addison-Wesley; 1969.

34. Brandt W. Positron dynamics in solids. Applied Physics. 1974;5(1):1-23.

35. Nanchevaa N, Dochevaa P, Mishevab M. Defects in $\mathrm{Cu}$ and $\mathrm{Cu}-\mathrm{O}$ films produced by reactive magnetron sputtering. Materials Letters. 1999;39(2): 81-85.

36. Turchi PE, Wachs AL, Wetzler KH, Kaiser JH, West RN, Jean $\mathrm{YC}$, et al. Electron momentum density studies in high-Tc materials by positron annihilation spectroscopy: theory and experiment. Journal of Physics: Condensed Matter. 1990; 2(6):1635-1658.

37. Ghijsen J, Tjeng LH, Elp JV, Eskes H, Westerink J, Sawatzky $\mathrm{GA}$, et al. Electronic structure of $\mathrm{Cu}_{2} \mathrm{O}$ and $\mathrm{CuO}$. Physical Review B. 1988;38(16): 11322-11330.

38. Stetten EC, Berko S, Li XS, Lee RR, Brynestad J, Singh $\mathrm{D}$, et al. High Sensitivity of positrons to oxygen vacancies and to copper-oxygen chain Disorder in $\mathrm{YBa}_{2} \mathrm{Cu}_{3} \mathrm{O}_{7-\mathrm{x}}$. Physical Review Letters. 1988;60(21):198-2201.

39. Hermes H, Forster M, Schaefer HE. High-temperature equilibrium study of the oxygen-site occupancy in $\mathrm{YBa}_{2} \mathrm{Cu}_{3} \mathrm{O}_{7-\delta}$ by positron annihilation. Physical Review B. 1991;43(13):10399-10404. DOI: 10.1103/PhysRevB.43.10399

40. McMullen T, Jena P, Khanna SN, Li Y, Jensen KO. Positron trapping at defects in copper oxide superconductors. Physical Review B. 1991;43(13):10422-10430.

41. Ferrell RA. Theory of positron annihilation in solids. Reviews of Modern Physics. 1956;28(3):308-337.

42. Clement M, de Nijs JM, Balk P, Schut H, van Veen A. Analysis of positron beam data by the combined use of the shape- and wing-parameters. Journal of Applied Physics. 1996;79(12):90299036.

43. de la Cruz RM, Pareja R, Diaz L, Garcia-Ramos JV. Annealinginduced positron trapping in $\mathrm{Cu}_{2} \mathrm{O}$ single crystals. Solid State Communications. 1989;71(2):93-95. DOI: 10.1016/00381098(89)90441-9 